\title{
CIUDADANÍA GADITANA, TRIBUTACIÓNY \\ TERRITORIALIDAD EN \\ LA AUDIENCIA DE \\ QUITO: EL CENSO \\ CONSTITUCIONAL DE \\ 1813 Y EL PLAN DE \\ ELECCIONES
}

Contato

Universidad Andina Simón Bolívar Sede Ecuador - Área de Historia Av. Toledo N22-80 (Plaza Brasilia) Edif.: José Joaquín Olmedo, piso 3 17-12-569 - Quito - Ecuador santiago.cabrera@uasb.edu.ec scabrerahanna@gmail.com

\section{(1) Santiago Cabrera Hanna*}

\author{
Universidad Andina Simón Bolívar \\ Quito - Ecuador
}

\section{Resumen}

Este artículo estudia, de manera preliminar, las formas que tomó la ciudadanía gaditana en la audiencia de Quito, en 1813. El argumento central del artículo es que dicha ciudadanía se basó en los esfuerzos borbónicos de incorporación periférica con propósitos fiscales. Los registros censales impulsados por la monarquía con el objetivo de volver más eficiente la recaudación de los impuestos y ampliar la masa tributaria fueron la base de los ejercicios censales constitucionales, cuyo objetivo era determinar el número de ciudadanos en cada distrito para integrar nuevos ayuntamientos que tuviesen como propósito la realización de elecciones. En este orden de cosas, se estudian aquí el censo de 1813, ordenado por Torivio Montes, y el Plan de Elecciones para la audiencia de Quito.

\section{Palabras-clave}

Audiencia de Quito - 1813 - ciudadanía - censo - Plan de Elecciones - cultura fiscal.

Doctor por el Programa de Pós-graduação em História Social del Departamento de História de la Faculdade de Filosofia, Letras e Ciências Humanas de la Universidad de São Paulo (USP), Profesor agregado del Área de Historia de la Universidad Andina Simón Bolívar, Sede Ecuador (UASB-E). 


\title{
THE CADIZ CITIZENSHIP,
}

TAXES AND

\section{TERRITORIALLTY IN THE \\ AUDIENCE OF QUITO: \\ THE CONSTITUTIONAL \\ CENSUS OF 1813 \\ AND THE "PLAN DE \\ ELECCIONES"}

Contact

Universidad Andina Simón Bolívar Sede Ecuador - Área de Historia Av. Toledo N22-80 (Plaza Brasilia) Edif.: José Joaquín Olmedo, piso 3 17-12-569 - Quito - Ecuador santiago.cabrera@uasb.edu.ec scabrerahanna@gmail.com

\section{(1) Santiago Cabrera Hanna}

Universidad Andina Simón Bolívar

Quito - Ecuador

\begin{abstract}
This article is a preliminary study of the forms which took the Cadiz citizenship in the audience of Quito, in 1813. The central argument of the article is that such citizenship was based on the Bourbon efforts of peripheral incorporation for tax purposes. Census records ordering by the monarchy in order to turn the tax collection more efficient and expand the tax mass were the basis of the constitutional census exercises, whose objective was to determine the number of citizens in each district to integrate new municipalities that had as purpose the conduct of elections. The contribution studies the 1813 census, ordered by Torivio Montes, and the Plan of Elections for the audience of Quito.
\end{abstract}

\section{Keywords}

Audience of Quito - 1813 - citizenship - census - Plan of Elections - taxes. 


\section{Introducción}

¿Qué ocurrió en la audiencia de Quito con los marcos políticos que definían la ciudadanía, luego de la inserción de la Constitución de Cádiz? En el contexto hispanoamericano las novedades gaditanas se toparon con un mosaico de antecedentes políticos, alimentado por expectativas formuladas por una serie de actores que, durante la crisis de la monarquía, establecieron juntas autonómicas de gobierno. Juntas que, al mismo tiempo que expresaban su lealtad a Fernando VII y su rechazo a las pretensiones napoleónicas sobre el imperio español, aprovecharon la coyuntura para replantear sus propias aspiraciones territoriales y jurisdiccionales. La necesidad de mantener unificados los espacios virreinales y audienciales también se tradujo en una búsqueda de hegemonía política reclamada por las juntas, a manera de pedidos de apoyo y lealtad. O de iniciativas tomadas desde los viejos cabildos. ${ }^{1}$

La segunda Junta Superior de 1810, creada luego del fracaso de la Junta Soberana de 1809, propuso la creación de un "Estado de Quito" con el respaldo de las demás provincias del reino, las cuales debían jurar su lealtad al gobierno presidido por el obispo neogranadino José Cuero y Caicedo, y enviar sus delegados al Supremo Congreso. El encargo del Congreso sería la promulgación de un texto constitucional, con el que la audiencia transitaría de un estatuto colonial a uno "moderno", y en el que la idea misma de "estado" señalaba la organización de un gobierno autónomo entre los virreinatos de Nueva Granada y el Perú.

La entrada en la audiencia de las tropas realistas comandadas por Torivio Montes, durante 1812, puso fin a aquel segundo experimento juntero, y dio paso a la reorganización política del territorio sobre la base de la Constitución de Cádiz. Por medio de este instrumento, los mecanismos de participación trazados por la junta y sus representantes en el Supremo Congreso, dieron al traste. Se impuso un delieamiento normativo de la ciudadanía política que dependería de la Constitución. Para lo cual era imprescindible establecer la fisonomía territorial de dicha participación por medio de un censo poblacional, destinado a señalar dónde y cómo se organizarían los

\footnotetext{
${ }^{1}$ DYM, Jordana. From Sovereign Villages to National States: City, State and Federation in Central America, 1759-1839. Albuquerque: University of Mexico Press, 2006; Idem. Actas de independencia: de la Capitanía General de Guatemala a la República Federal de Guatemala. In: PALACIOS, Marco (ed.). Las independencias hispanoamericanas: Interpretaciones 200 años después. Bogotá: Grupo Editorial Norma, 2009, p. 339-366.
} 
nuevos ayuntamientos, quiénes estarían a cargo de preparar los listados que alimentarían el conteo y cuál sería el rol interpretado por los municipios de las ciudades más grandes.

Este artículo estudia el censo de 1813, ordenado por el presidente Montes y el Plan de Elecciones puesto en marcha como base de la ciudadanía gaditana en la audiencia de Quito, luego del cierre del ciclo juntero. Me interesa aquilatar estas fuentes como recursos que hicieron posible la redefinición territorial de la participación política en la audiencia y la "desmonopolización" de la hegemonía política de las ciudades más grandes, al facultar la creación de ayuntamientos constitucionales sobre la base de un coeficiente mínimo de votantes. Sostengo que el censo produjo un dibujo constitucional calcado sobre los viejos parámetros de conteo de la población, instituidos por la monarquía borbónica con propósitos fiscales. Al hacerlo, la fiscalidad del Antiguo Régimen sentó las bases territoriales y sociales de la ciudadanía gaditana en la audiencia de Quito. ${ }^{2}$

\section{Una reconfiguración normativa y territorial de la ciudadanía política: El censo de 1813}

Sigo aquí el planteamiento de Federica Morelli quien ha puntualizado que la Constitución de Cádiz, al tiempo que fue un recurso político de normalización de la ciudadanía, en lugar de constreñir los modos en que ésta se definía, abrió la posibilidad de que se tramitara según los atributos locales de identificación de los sujetos políticos, como la vecindad. Este informante social fue, entre otros, la base de la configuración de la sujetidad política promovida por el doceañismo. ${ }^{3}$ En virtud de aquello, eran los cuerpos de gobierno locales (cabildos) quienes establecían el tipo de integración política de los habitantes dentro de sus circunscripciones. Estos "cuerpos intermedios", presentes dentro de la cultura castellana entre el monarca y sus va-

\footnotetext{
2 La cultura fiscal en el Ecuador durante la transición de la colonia a la república ha sido escasamente estudiada. Se conocen solo dos trabajos importantes: RODRÍGUEZ, Linda Alexander. Las finanzas públicas en el Ecuador (1830-1940). Quito: Banco Central del Ecuador, 1992; VELASCO HERRERA, Viviana. Negociar el poder: Fiscalidad y administración pública en el proceso de construcción del Estado ecuatoriano, 1830-1875. Disertación de doctorado, Universitat Pompeu Fabra, 2013. Las articulaciones entre fiscalidad y ciudadanía política durante la crisis imperial ibérica son, todavía, una tarea pendiente de la producción historiográfica ecuatoriana. Tarea en la que se inscribe este artículo.

3 HERZOG, Tamar. Vecinos y extranjeros: Hacerse español en la edad moderna. Madrid: Alianza, 2006.
} 
sallos, fuero piezas clave del ordenamiento jurídico imperial, y fundamento de las posteriores acciones políticas durante la crisis. ${ }^{4}$

Pero además, el constitucionalismo gaditano hizo posible que esas entidades efectuaran la incorporación social de actores que, hasta el momento de su entrada en vigencia, no gozaban del estatuto de ciudadanos, y que habían estado al margen, incluso de los ejercicios de reconocimiento locales de los cabildos coloniales. ${ }^{5}$

La orden de realizar un censo para determinar el número de personas susceptibles de ser reconocidas como ciudadanos dentro del reino, como punto de partida para la erección de los ayuntamientos constitucionales, desarregló las hegemonías territoriales y jurisdiccionales de los viejos cabildos locales que, como el de Quito, mantenían el control de poblaciones menores dentro del distrito. Aquellas hegemonías sostenían el funcionamiento de complejos sistemas de alianzas políticas y económicas entre las elites locales, el gobierno de las poblaciones indígenas, el clero y los corregidores. Además, era posible, en virtud de tales pactos, condicionar las lealtades locales a cambio de la eventual concesión de cabildos o el cambio en los estatutos jurisdiccionales de esas poblaciones, según constata Morelli. ${ }^{6}$

\section{Un censo constitucional con basamentos fiscales: Los "materiales" del conteo}

Como se ha sugerido, Montes priorizó el censo para identificar los lugares donde se abrirían los nuevos ayuntamientos, y determinar el número de personas sobre las cuales recaería el estatus de ciudadanos constitucionalmente habilitados para participar en los comicios que elegirían a los delegados del reino. Los elegidos votarían tanto por los delegados ante las Cortes peninsulares, como por los de cada partido en elecciones indirectas de segundo y tercer grados. Los responsables de los conteos en cada distrito

\footnotetext{
${ }^{4}$ MORELLI, Federica. Territorio o nación: Reforma y disolución del espacio imperial en Ecuador (1765-1830). Madrid: Centro de Estudios Políticos Constitucionales (CEPC), 2005.

5 RODRÍGUEZ ORDÓÑEZ, Jaime E. La independencia de la América española. México: Fondo de Cultura Económica, 2005; e Idem. La revolución política en la época de independencia: El Reino de Quito, 1808-1822. Quito: Corporación Editora Nacional / UASB-E, 2007.

6 “(...) el cambio más importante es la obtención por parte de Alausí, Latacunga, Ambato y Otavalo del estatuto de villas, que les dio jurídicamente el derecho de elegir un cabildo; derecho que ejercieron desde comienzos de 1812, según procedimiento dictado por la junta quiteña". MORELLI, Federica. Territorio o nación..., op. cit., p. 215.
} 
serían los cabildos constitucionales, los obispados y el clero parroquial, una tríada estamental que mantenía control de información sobre sus poblaciones y que, dadas sus capacidades logísticas y cercanías sociales, podía efectuar los conteos:

(...): Para que se de principio a ello en esa Capital, procedente de sus Parroquias, yeno de las sinco leguas desu actual [ilegible] a la elección de Electores, que hande concurrir a la del Ayuntamiento, congregándose al eflecto] todos sus respectivos vecinos el veinte ynuebe del presente mes, (que se designa) precedidas las Juntas Parroquiales por las personas, que nombrara esta Capitania General a las que pasara las convenientes ordenes, siendo de su cuidado, como del desus Parrocos y el resultado de dichas elecciones se siente por acta en los libros que deveran formar, comunicando a los electores copia autorisada de ella para que hagan constar la legitimidad de sus personas, en la presentación de sus sufragios en la elección de los oficiales, de los oficiales, de los que se hade componer el Ayuntamiento, hasta el numero de dos alcaldes, dies y seis Regidores y dos Procuradores Sindicos. ${ }^{7}$

Comúnmente, los listados, padrones y padroncillos eran preparados para identificar las bases sociales de la política fiscal colonial, el control de la fuerza de trabajo y la integración de los contingentes de milicias. ${ }^{8}$ Los Borbones institucionalizaron los registros censales a una escala mayor a los conteos locales, para aproximar un dato más completo sobre número de habitantes, que permitiese incrementar la masa tributaria y tornar eficiente su recaudación, maximizando el número de contribuyentes. ${ }^{9}$ Además, se quería establecer el número de personas capaces de tomar las armas ante eventuales incursiones armadas. ${ }^{10}$

De ninguna manera se trataba de registros exactos. Eran más bien conteos realizados a partir de información previa, que se completaba, en el mejor de los casos, con información obtenida de primera mano. El cotejo era siempre problemático por la inexactitud de la información previamente le-

\footnotetext{
7 ANH-Q, Serie Gobierno, caja 68, exp. 17, f. 1 y 1/r. La ortografía consta así en el original. También citado en CABRERA HANNA, Santiago. Ciudadanía, representación política y territorio en la audiencia de Quito: Entre el Pacto Solemne de 1812 y el censo poblacional de 1813. Memoria y Sociedad, vol. 20, n. 41, 2016, p. 119. DOI: http://dx.doi.org/10.11144/Javeriana.mys20-41.crpt

8 MINCHOM, Martin. La evolución demográfica del Ecuador en el siglo XIX. Cultura, vol. VIII, n. 24b, 1986, p. 460.

9 ORTIZ DE LA TABLA, Javier. La población tributaria del Ecuador colonial. Cultura, vol. VIII, n. 24b, 1986, p. 456.

${ }^{10}$ Véase JUAN, Jorge \& ULLOA, Antonio de. Noticias secretas de América. Parte I - Sobre el estado militar y político de las costas del Mar Pacífico. Madrid-Quito: Turner / Libri Mundi, 1982.
} 
vantada, y por causa de los avatares a los que se enfrentaban quienes debían realizar los registros. Por lo general, los documentos locales que proporcionaban información sobre las poblaciones para los empadronamientos fueron actas bautismales y de decesos, pertenecientes al clero secular; padrones y padroncillos sobre el manejo de las Cajas Reales, y libros de cabildo en las ciudades y haciendas. Estos registros se llevaban a cabo empleando a la burocracia local, que funcionaba y vivía en las periferias sociales y materiales del imperio (como corregidores y alcaldes pedáneos) y también con la ayuda del clero parroquial:

Fue (...) uno de los atributos de la post-reforma de la escritura burocrática el que se requiera información en una escala en que la burocracia borbónica no podía proveer bien y que pudiera ser complicada por un llamado oficial en la capital virreinal de Bogotá, que no tenía un conocimiento de primera mano acerca de la provincia. ${ }^{11}$

El antecedente más importante de estos conteos fue el ordenado entre 1778 y 1781 por el presidente de la audiencia Josef de Villalengua, dentro de la política fiscal borbónica. Este conteo estableció una serie de informaciones con las cuales fueron "completados" los vacíos en los resultados del censo de 1813 o permitieron el cotejo de datos censales. El escrutinio realizado por Kenneth Andrien sobre el "censo de Villalengua" permite derivar una serie de conclusiones en torno de la población de la audiencia susceptible de imposiciones fiscales (de las cuales la más importante, según sabemos, era la tributación indígena). Casi el 63\% de la población empadronada era indígena (un número cercano a 278.000 habitantes); las castas y otros grupos de población africana mantenían un porcentaje cercano al 11\%) (aproximadamente 48.000 personas). Los grupos considerados blancos y blanco mestizos se aproximaban al 26\%. Esta población se concentraba especialmente en la región centro y norte de la audiencia, en el corregimiento de Riobamba y los espacios circundantes a la sede de la audiencia, las "cinco leguas de Quito" (Latacunga, Ambato, Ibarra y el asiento de Otavalo). ${ }^{12}$

Si se toman estos datos para cotejarlos con la distribución geográfica de los centros urbanos más importantes de la audiencia de Quito (la propia sede y las cabeceras de los corregimientos más importantes), es posible esta-

\footnotetext{
${ }_{11}$ MINCHOM, Martin. La evolución demográfica..., op. cit., p. 460.

${ }^{12}$ ANDRIEN, Kenneth. The Kingdom of Quito, 1690-1830: The State and Regional Development. Cambridge: Cambridge University Press, 1995; ORTIZ DE LA TABLA, Javier. La población tributaria..., op. cit., p. $447-458$.
} 
blecer los pesos jurisdiccionales de estas ciudades regionales en relación con la ciudad de Quito, el corregimiento de Riobamba (centro y norte del espacio audiencial), y en los alrededores de la ciudad de Cuenca (en la región sureña del reino). Los coeficientes de centralidad que dependen de la densidad poblacional, así como de la concentración de organismos administrativos y centros de decisión política y económica, coinciden con la concentración de la población indígena en la región altiplánica del país, señalando las regiones de Quito y Riobamba como los distritos más densamente poblados y, por ende, con mayor capacidad tributaria. Este dato será el que, para Montes, constituiría el referente clave de los resultados del "censo constitucional de 1813", tramado sobre el bastidor tributario del conteo de Villalengua.

\section{Esguinces censales que redefinen territorialidades: La agregación de resultados como recurso de incorporación nominal}

Recabar la información que alimentaría el censo constitucional planteó deslizamientos prácticos en relación con los ejercicios censales previos. Uno de ellos tuvo que ver con la delegación directa de quienes debían realizar los padrones en cada distrito. Si en el censo fiscal de 1778-1781 la responsabilidad de los conteos recayó sobre la burocracia local encabezada por los corregidores, en el bando que ordenaba el "censo constitucional" Montes designaba directamente a los funcionarios que debían hacerlo. Suponemos que esta disposición dejó sus huellas en los resultados del registro (ya que en muchos casos, los criterios de pertenencia territorial y cercanía social hacían posible un conteo más fidedigno a las realidades locales: pueblos, asientos y villas), y alienaron los vínculos entre los antiguos corregidores, jueces pedáneos, caciques y la población local.

Tal circunstancia hacía que los conteos resultaran todavía más inexactos, o con una serie de vacíos que para efectos de la instalación de los ayuntamientos, ocasionaba serios problemas. En varias circunscripciones los conteos establecieron un escaso número de censados, lo cual reducía el porcentaje de población que podía ser considerada como ciudadana, con lo cual las posibilidades de establecer ayuntamientos constitucionales se reducían. La articulación entre los resultados del conteo y el nivel de representación política que deseaba obtenerse pasaba por la capacidad poblacional de cada circunscripción, en el sentido de acreditar un número base de mil personas. Allí donde no fuese posible arribar a ese facultativo número, habría que hacer una serie de ajustes numéricos. ¿Cómo se sortearon esos escollos? 
Una alternativa fueron las "agregaciones". Estas consistían en la adición del número de pobladores de una circunscripción a los de otra, hasta llegar al número base de personas que permitiría la instalación del ayuntamiento. En tales ejercicios, el censo de Montes siguió la división territorial del antiguo sistema de corregimientos e identificó dieciséis partidos dentro de la audiencia: Ybarra, Otavalo, Pastos, Pasto, Barbacoas y la Costa, Quito, Cuenca, Riobamba, Macas, Alausí, Ambato, Guaranda, Latacunga, Loxa y Jaen de Bracamoros. ${ }^{13}$ Esta era una agregación territorial que combinaba criterios jurisdiccionales pertenecientes al viejo sistema de corregimientos, así como necesidades del propio conteo poblacional, que adicionaban resultados en función de las articulaciones regionales de cada circunscripción, pero también a partir de una sumatoria simple de resultados.

Otro recurso era la "adición completa" de padrones o padroncillos previos. Esto permitía completar todo el registro correspondiente a una o varias circunscripciones, sin cotejar esos datos, sino apenas como complemento del registro efectuado con fines electorales. Este fue el caso del registro de 1748, agregado enteramente para el caso de las "cinco leguas" de Quito. En ambas formas de adición de los resultados, el ejercicio censal configuraba, en la práctica, un panorama territorial en el que se ponían en juego diversas expectativas de hegemonía territorial, que tomaban forma en el ejercicio mismo de incorporación nominal de unas circunscripciones a otras.

Lo cual, si bien obedecía a un criterio de racionalización práctica que permitía el desarrollo del censo constitucional de forma más o menos rápida, también complicaba las expectativas de hegemonía jurisdiccional sobre otros pueblos:

(...) se agregó el Censo ò Padròn del año de 1784, relativo à Quito, y sus treinta pueblos; (...) que es el último que hay de los que se practicaron en cumplimiento de la Real Orden de 1776, y las noticias que se adquirieron en observancia de la Orden Superior de 29 de Agosto de 1807, haviendose encontrado de las relaciones dadas entonces cuatro en (...) otros tantos pueblos de las cinco leguas de esta ciudad con los de Latacunga, Riobamba, Alausí, Guaranda, Loza, Zaruma y Bracamoros; los de Otavalo, è Ybarra, advirtiéndose que por lo que mira a algunos Pueblos y Provincias falta el artículo de numeración por haberse encargado este punto al cuidado del Ylmo. Sr. Obispo; de modo que para el cálculo prudencial, que ha de hacerse se echan de menos las respectivas noticias en cuanto a la población de Ambato de las Provincias de la antigua jurisdicción

\footnotetext{
${ }^{13}$ Plan de Elecciones de Diputados en Cortes, y de Provincia (1813), ANH-Q, serie Gobierno, caja 68, 26.viii.1813, ff. 19-22, 31. Cf. RODRÍGUEZ O. La revolución política..., op. cit., p. 218-224.
} 
gubernativa de Popayán, con la de Macas, Esmeraldas y su Costa, la de Loxa, la de esta capital y sus cinco leguas. ${ }^{14}$

La división administrativa usada en el conteo constitucional no alteraba la segmentación territorial de los anteriores padrones levantados para el cobro de las Cajas Reales. Según el reglamento proporcionado a los delegados de Montes, sería reconocido como votante todo ciudadano español, incluidos los indígenas, los vecinos de las parroquias y eclesiásticos y clero secular. Y quedarían excluidos los esclavos, sirvientes domésticos y extranjeros, a no ser que exhibieran una carta de ciudadanía o libertad, en el caso de las castas. ${ }^{15}$

El constitucionalismo doceañista permitía que la silueta de la ciudadanía fuese delineada por convenciones locales de reciprocidad, como la vecindad: si bien, como señala Cristóbal Aljovín, el propio constitucionalismo gaditano dio inicio a la separación de la dupla vecindad-ciudadanía, arraigando la primera en las dimensiones locales de su significación y la otra en las balizas normativas de su configuración. ${ }^{16}$ Además de producirse un distanciamiento entre ambos elementos de la dupla en términos de una configuración socioterritorial, en la cual la vecindad iría ancorándose en el ámbito de lo rural, y la ciudadanía dentro de los trazados urbanos. Pero en dicho distanciamiento los parámetros fiscales de la política borbónica sentaban las bases del nuevo conteo y, con ello, se insertaban dentro de los delineamientos prácticos de la nueva ciudadanía política. Puede decirse, según propongo, que la fiscalidad borbónica devino en la informante clave de los mecanismos que, mediante el censo de 1813, establecieron los límites de la ciudadanía.

\section{Hegemonía territorial y comicios: El Plan de Elecciones}

Al mismo tiempo que se organizaba el censo, el bando promulgado por Montes establecía un Plan de Elecciones para todo el reino, que oficializaba, según lo dispuesto por la constitución gaditana, el tipo de rituales comicia-

\footnotetext{
${ }^{14}$ ANH-Q, serie Gobierno, caja 68, exp. 17, ff. 11; MAIGUASHCA, Juan. El proceso..., op. cit., p. 355-424; También citado en CABRERA HANNA, Santiago. Ciudadanía, representación política..., op. cit., p. 120.

${ }^{15}$ Nombramiento de electores por parroquias para la formación del ayuntamiento constitucional, ANH-Q, serie Gobierno, caja 68, exp. 17.

${ }^{16}$ ALJOVÍN, Cristóbal. Ciudadano y vecino en Iberoamérica, 1750-1850: Monarquía o República. In: FERNÁNDEZ, Javier (dir.). Diccionario político y social del mundo iberoamericano. La era de las revoluciones, 1750-1850. Madrid: Fundación Carolina / Sociedad Estatal de Conmemoraciones Culturales / CEPC, 2009, p. 179-197.
} 
les que debían celebrarse, una vez determinados el número y lugar de los ayuntamientos constitucionales. De acuerdo con el Plan, las elecciones en las circunscripciones seguirían un criterio proporcional para la selección de sus representantes. Esto dependía, ya lo he comentado, del número de censados.

En este esquema de funcionamiento, los compromisarios electos nominarían a "puerta cerrada" a los electores de parroquias, en elecciones de segundo grado. El ejercicio tenía por objetivo cumplir con dos necesidades: En primer lugar, recomponer el mapa de la representación política del reino, luego de la experiencia de la convocatoria del Supremo Congreso, hecha por la Junta Superior de 1810. Y, en segundo lugar, de manera indirecta, constreñir las funciones de representación política interpretadas por los cabildos de las ciudades más grandes, en favor de los ayuntamientos recién abiertos.

\section{Rituales gaditanos en ropajes de Antiguo Régimen}

La conformación de los ayuntamientos constitucionales iniciaba con una convocatoria general a los pobladores hecha por el párroco local, quien los reunía en una asamblea especial e iniciaba los comicios con un Te Deum. Los párrocos trabajaban en estrecha relación con los funcionarios designados por Montes durante todo el proceso electoral local, y en la formación misma de los ayuntamientos. En varios casos coadyuvaron al conteo de los votos. En el bando que designa a los funcionarios responsables de llevar adelante las elecciones locales aparecen descritas esas articulaciones:

$1^{\text {a }}$ En el momento que reciba V. esta orden la (persona) con Oficio al Parroco para que inteligenciado de las providencias combenientes a la citacion de los Vecinos y su reunion. $2^{\mathrm{a}}$ La eleccion se hara el Domingo proximo 29 del corriente trasladandose V. a la Parroquia que lo era señalada (...)

$6{ }^{\text {a }}$ Hecha la eleccion que se verificará en el que todos a lo menos la mayoría de un voto se sentará al presente oficio en tono de acta que firmada por V. el Parroco y secretario, se colocará en el libro Parroquial que debe normalisarse sacandose antes un testimonio integro firmado por V. el Parroco y Secretario, que se entregara al Electo. ${ }^{17}$

Los actos comiciales gaditanos se recubrían de la legitimidad simbólica proporcionada por la monarquía católica, sin la cual las actuaciones polí-

${ }_{17}$ ANH-Q, Caja 68, exp. 17, f, 3/r. (Énfasis añadido). La ortografía consta así en el original. 
ticas no podrían cristalizarse. ${ }^{18}$ Como antes se señaló, tanto en el contexto hispanoamericano como en el portugués americano, el papel comicial de los párrocos locales era indispensable para proporcionar información sobre la población, en función de las actas bautismales, registros de matrimonios o defunciones, y para cotejar el estatus de vecindad de los pobladores, cara a cara. ${ }^{19}$ Estas colaboraciones dejan entrever, además, un entramado de alianzas para incluir dentro de los padrones a grupos específicos de la población, cuya incorporación nominal se dirimía en función de relaciones de poder e intereses vinculados con las elites locales y el sistema de gobierno indígena. ${ }^{20}$ Los párrocos actuaban dentro de los ambivalentes sistemas de alianzas $\mathrm{y}$ acomodos de poder dentro de las comunidades indias. ${ }^{21}$

\section{Las texturas de la incorporación social gaditana}

La introducción de la Constitución de Cádiz produjo, además, un primer ensayo moderno de homogeneización social en términos normativos, ${ }^{22}$ que cumplía con dos propósitos devenidos del carácter legal emanado de

\footnotetext{
${ }^{18}$ DEMÉLAS, Marie-Danielle E SAINT-GEOURS, Yves. Jerusalén y Babilonia: Religión y política en el Ecuador, 1780-1880. Quito: IFEA / Corporación Editora Nacional, 1988, p. 21-32.

${ }^{19}$ SAINT-GEOURS, Yves. La Iglesia en la Independencia. In: G. CARRERA DAMAS (ed.). Historia de América Andina, vol. 4 - Crisis del régimen colonial e independencia. Quito: UASB-E / Libresa, 2003, p. 269-327; GUERRA, François-Xavier. Imaginarios y valores de 1808. Modernidad e independencias: Ensayos sobre las revoluciones hispánicas. Ciudad de México: Fondo de Cultura Económica, 2010, p. 149-175; y LYNCH, John. Dios en el Nuevo Mundo: Historia de la Iglesia de América Latina. Barcelona: Crítica, 2012; PRADO JR., Caio. Formação do Brasil contemporâneo: Colônia. São Paulo: Companhia das Letras, 2011, p. 33.

${ }^{20}$ Ana Luz Borrero ha estudiado detalladamente la convocatoria a elecciones de Montes, en el contexto del corregimiento de Cuenca, para desentrañar las relaciones de poder establecidas entre grupos de poder representados en el cabildo de la sede del corregimiento y los representantes del gobierno indígena. Estas articulaciones dieron paso a una serie de negociaciones para incluir en los padrones a ciertos indígenas, y a otros no. BORRERO, Ana Luz. El legado de Cádiz: ciudadanía y cultura política en la Gobernación de Cuenca, 1812-1814. Procesos, n. 39, enero-junio 2014, p. 36; e Idem. Cuenca en la Independencia, de la fidelidad a la insurgencia: 18091824. Disertación de doctorado, UASB-E, 2016, p. 9-36.

${ }^{21}$ CORONEL, Rosario. Poder local entre la Colonia y la República: Riobamba, 1750-1812. Quito: UASB-E / Corporación Editora Nacional, 2015.

${ }^{22}$ MAIGUASHCA, Juan. El proceso de integración nacional en el Ecuador: el rol del poder central. In: Idem (ed.). Historia y región en Ecuador: 1830-1930. Quito: Flacso-Cerlac / York University / IFEA / Corporación Editora Nacional, 1994, p. 355-420; CABRERA HANNA, Santiago. Repensando el Estado como institución. Poder central, cultura local y relaciones centro-periferia en las intepretaciones de Juan Maiguashca y el debate Schwarz-Carvalho Franco. Almanack, n. 13, 2016, p. 153-183. DOI: http://dx.doi.org/10.1590/2236-463320161308.
} 
la propia constitución y acordes con los variados contextos en los que se introducía. En primer lugar, se procuraba dotar de un sentido legal a unas formas de ejercicio de la ciudadanía determinadas (desde 1808 a 1812) por nociones locales bajo la contingente definición de vecindad, en función de intereses locales de traslape de unas poblaciones sobre otras en el ejercicio de la representación. En teoría, los artículos de la Constitución dedicados a caracterizar al ciudadano vendrían a desbancar dichas apropiaciones y a normar una participación política determinada por prácticas comúnmente aceptadas en los encuadres locales. En segundo lugar, se quería establecer, de la manera más acotada posible, el número de pobladores de la audiencia capaces de ejercer la ciudadanía política como derecho.

Las elecciones realizadas en 1813 estuvieron destinadas no solo a elegir a los electores de los representantes del reino ante las cortes metropolitanas, sino también a identificar a los representantes de pueblos y ciudades (compromisarios); con ello se recomponía el rostro de la representación local con arreglo a la Constitución, para regular la influencia de los ayuntamientos locales en la vida política local.

Era un intento de incorporación social de las poblaciones con base en su prefiguración como ciudadanos, que se sostuvo sobre las estructuras administrativas tributarias del sistema de corregimientos. ${ }^{23}$ Tal prefiguración supuso la segregación de otros sectores que, o venían ejerciendo la representación política a partir de las nociones de pertenencia y vecindad pregaditanas, o no podían integrarse a los sistemas representativos, por ser forasteros. ${ }^{24}$

A Montes, la proclamación de Cádiz también le sería útil para restar hegemonía territorial a la región de Quito sobre las otras dos ciudades regionales (Cuenca y Guayaquil), desarticulando sus formas de incorporación e instaurando otras, con base en la erección de nuevos ayuntamientos, la redefinición de los patrones de representación local y en la posibilidad de elegir electores para diputados en periferias territoriales que no estaban políticamente incorporadas.

\section{¿Soberanía municipal o soberanías municipales?}

La fragmentación de los cabildos urbanos, luego del censo de 1813, redefinió el sistema administrativo de la sierra centro-norte, montado sobre

\footnotetext{
${ }^{25}$ MAIGUASHCA, Juan. El proceso de integración..., op. cit

${ }^{24}$ HERZOG, Tamar. Vecinos y extranjeros..., op. cit.
} 
la hegemonía territorial del municipio capitalino, y sobre los concejos municipales de Ibarra y Riobamba, las urbes que le seguían en coeficiente de centralidad y en número de población. Sin embargo, en la integración de esos nuevos ayuntamientos constitucionales, el gobierno local quiteño mantendría niveles importantes de participación, al usar sus rentas propias para facilitar la conformación de esos nuevos entes políticos y en la construcción de obra pública que permitiese la convocatoria y reunión de los vecinos de las circunscripciones, al momento del llamado a elecciones. ${ }^{25}$

De modo que, si bien el cabildo de la sede de la audiencia perdía su hegemonía jurisdiccional y administrativa, gracias a la apertura de esos nuevos espacios de participación política, quedaba obligado por disposición del presidente de la audiencia, a garantizar que tales ayuntamientos pudiesen funcionar. De acuerdo con el "Expediente sobre la formación del Ayuntamiento Constitucional de esta capital, nombramiento de elecciones y consequentes diligencias para las diputaciones especiales", se contabilizaban 25 pueblos, cuya designación de electores podría incluso exceder la prevista en la Constitución. ${ }^{26}$

Como ya señalé, el constitucionalismo doceañista abrió paso a la inclusión política de un conjunto de actores que estaban al margen de su intervención, dentro de los marcos jurisdiccionales administrativos de las ciudades, cuyo monopolio debía ser revocado, para promover la participación política e incorporar nuevas periferias sociales. Tales proyecciones precipitaron la fragmentación del territorio quiteño, entre 1812-14 y 182022 y limitaron el rango de acción de su gobierno local. De esta manera, no solo la participación política se amplificaba y se diseminaban los ejercicios de soberanía local. Se redefinían, también, los mecanismos administrativos vinculados a la política fiscal que veía incrementar su base de recaudación en vista de la creación de nuevas estructuras municipales.

\footnotetext{
25 “(...) Esta ciudad posee rentas suficientes á mantener su Policía en el mejor estado, y atender al mismo tiempo á la construcción de Puentes y Calzadas, y al reparo de caminos: no sucedería así con los Cabildos de nueba formación de modo que si se les dejase en la demarcación de los ayuntamientos de parroquias se imposibilitaría la composición de las sendas públicas que la mayor parte del año están impracticables. Dese pues la norma por esta capital cuidando inmediatamente su cabildo de poner en un pie de solida refacción, los caminos, y formándose en seguida los Ayuntamientos y Villas de esta Capitanía general, se procederá a establecerlos sin demora en los Pueblos del vecindario competente, bajo las más adecuadas divisiones: (...)." ANH-Q. Expediente principiado y seguido sobre la formación del Ayuntamiento Constitucional de esta capital, nombramiento de elecciones y consequentes diligencias para las diputaciones especiales, fol. 7. ${ }^{26}$ Idem.
} 
Los artículos de la constitución de Cádiz, que establecían el tipo de personas sobre las cuales recaía el estatus de la ciudadanía, fueron lo suficientemente amplios como para permitir que el reconocimiento de los sujetos políticos ocurriese dentro de los paradigmas locales de la vecindad y en función del cumplimiento de un conjunto de requisitos laxos. ${ }^{27}$ En dicho reconocimiento, la participación de las autoridades municipales fue fundamental: "Art. 18. Son ciudadanos aquellos españoles que por ambas líneas traen su origen de los dominios españoles de ambos hemisferios, y están avecindados en cualquier pueblo de los mismos dominios". ${ }^{28}$

Además, la soberanía municipal puesta en juego durante la crisis hispánica proporcionó a los alcaldes ordinarios un rol adicional al de la administración de la justicia jurisdiccional. Con atribuciones políticas entre las cuales estaban la obligación de presidir los rituales electorales y promover el voto de sus comunidades, los alcaldes cerraban un circuito de poder dentro del cual pasaron a ejercer una autoridad emanada no solo de las atribuciones y funciones del cabildo castellano. Se transfiguraron en intermediarios de la soberanía local, pues pasaron a dictaminar sentencias no solo dentro de la justicia comunitaria; además intervenían directamente en las decisiones sobre quiénes eran sujetos de la representación política y quiénes no: quiénes estaban en condiciones de ser incluidos como ciudadanos y quiénes quedaban fuera. Esta fue una de las cuestiones más problemáticas a resolverse, en vista de los criterios que se seguirían para efectuar las agregaciones políticas, que permitiesen abrir la mayor cantidad de ayuntamientos constitucionales y juntas electorales.

En cuanto a los roles políticos y administrativos del gobierno local en la aplicación de la justicia local, el doceañismo gaditano no introdujo innovaciones significativas. Salvo que el rol de jueces de primera instancia con los cuales operaban los alcaldes ordinarios se constitucionalizó y con ello se revistió de una doble legitimidad en su influencia sobre la vida comunal: la proveniente del carácter corporativo del cabildo, como "cabeza" de un "cuerpo social" reconocido orgánicamente como parte de una entidad política mayor (la nación); y la emanada del corpus de artículos constitucionales

\footnotetext{
${ }^{27}$ HERZOG, Tamar. Vecinos y extranjeros..., op. cit.; MORELLI, Federica. Territorio o nación..., op. cit.

${ }^{28}$ Constitución política de la monarquía..., op. cit., p. 2.
} 
forjados desde las balizas políticas liberales impulsadas por el constitucionalismo gaditano. ${ }^{29}$

La codificación gaditana facultaba la agregación de poblaciones menores, para constituir corporaciones electorales con base en criterios muy elementales de adición de las poblaciones provenientes de los resultados censales:

Art. 38. En las juntas de parroquia se nombrará por cada doscientos vecinos un elector parroquial.

Art. 39. Si el número de vecinos de la parroquia excediese de trescientos, aunque no llegue a cuatrocientos, se nombrarán dos electores; si excediese de quinientos, aunque no llegue a seiscientos, se nombrarán tres, y así progresivamente.

Art. 40. En las parroquias, cuyo número de vecinos no llegue a doscientos, con tal que tengan ciento cincuenta, se nombrará ya un elector; y en aquellas en que no haya este número, se reunirán los vecinos a los de otra inmediata para nombrar el elector o electores que les corresponda. ${ }^{30}$

La agregación de parroquias redefinió los marcos de la administración territorial y, finalmente, modificó las formas comunales de conformación de sus identidades culturales, en vista de que el criterio para la anexión se justificaba en la cobertura de déficits poblacionales, que debían alcanzar un número mínimo de personas facultadas como ciudadanos y conseguir una representación indirecta, por medio de compromisarios. La agregación tenía fundamentos administrativos y no necesariamente identitarios: o sea, se añadían poblaciones para cubrir faltantes numéricos y no necesariamente atendiendo vínculos territoriales, sociales o culturales. Además, se efectuaron por la necesidad de "recontar" los habitantes en circunscripciones menores, porque los padroncillos y enumeraciones anteriores eran inexactos. ${ }^{31}$

\footnotetext{
29 “(...) a pesar de la introducción de principios como la separación de poderes, la supremacía del legislativo y la subordinación del juez a la normativa procedente de aquél, la justicia no se cambió". MORELLI, Federica. Pueblos, alcaldes y municipios : La justicia local en el mundo hispánico entre Antiguo Régimen y Liberalismo. Historia Crítica, no. 36, julio-diciembre 2008, p. $45 .$.

${ }^{30}$ Constitución política de la nación..., op. cit., p. 5.

${ }^{31}$ Esto fue lo que ocurrió, por ejemplo, en el caso de Riobamba, Cuenca y Alausí, agregadas en vista de que estas eran las únicas poblaciones de las cuales se tenía información censal previa. "Respecto á que según la nota marginal, los censos á que se refiere, son solamente comprendidos los de las provincias de Riobamba, Cuenca y Alausí: Para que el calculo, de que se trata, se actúe con la exactitud que sea dable; la Secretaría pondrá corrientes los censos autenticos de las demás Provincias, que existan, aunque anteriores, haciendo de ellas noticia al Abogado Fiscal". ANH-Q. Expediente principiado y seguido sobre la formación del Ayuntamiento Constitucional de esta capital, nombramiento de elecciones y consequentes diligencias para
} 
En cuanto al gobierno local municipal, el doceañismo gaditano intervino directamente en su naturaleza corporativa, con una serie de artículos destinados a limitar la influencia de los grupos de poder en la representación local y armonizar los mecanismos de selección de sus autoridades según los principios liberales de la Carta. ${ }^{32}$ Con ello se buscaba - es mi opinión supeditar los roles jurisdiccionales (la impartición de la justicia con base en leyes de costumbre) y administrativos del cabildo (su carácter gubernativo en términos de la periferia social que representaba) al retocar los marcos normativos de la representación:

Art. 312. Los alcaldes, regidores y procuradores síndicos se nombrarán por elección en los pueblos, cesando los regidores y demás que sirvan oficios perpetuos en los ayuntamientos, cualquiera que sea su título y denominación.

Art. 313. Todos los años en el mes de Diciembre se reunirán los ciudadanos de cada pueblo, para elegir a pluralidad de votos, con proporción a su vecindario, determinado número de electores, que residan en el mismo pueblo y estén en el ejercicio de los derechos de ciudadano.

Art. 314. Los electores nombrarán en el mismo mes a pluralidad absoluta de votos el alcalde o alcaldes, regidores y procurador o procuradores síndicos, para que entren a ejercer sus cargos el primero de Enero del siguiente año. ${ }^{33}$

Si bien las responsabilidades internas del cabildo, amén de sus funciones administrativas, eran las mismas que las que ostentaba en el contexto pregaditano, otras novedades estuvieron en la posibilidad de incorporar nuevos actores políticos que podían, con base en el reconocimiento de su ciudadanía, ser elegidos como representantes de la localidad en el cabildo. Con ello, la fisonomía social del gobierno local anterior a 1812 - fundamentalmente nobiliario - se alteró notablemente. Por ejemplo, la marcada influencia de los clanes familiares más importantes de la región (Selva Alegre

\footnotetext{
las diputaciones especiales, fol. 11 vr. La ortografía consta así en el original. Vid.: CABRERA HANNA, Santiago. Ciudadanía, representación política..., op. cit., p. 120.

32 TERNAVASIO, Marcela. 1. Sufragio y Revolución. In: Idem. La revolución del voto: Política y elecciones en Buenos Aires, 1810-1852. Buenos Aires: Siglo Veintiuno, 2002, p. 27-51; ANNINO, Antonio (coord.). Historia de las elecciones en Iberoamérica: Siglo XIX. Buenos Aires: Fondo de Cultura Económica, 1995; DEMÉLAS, Marie-Danielle. Modalidades y significación de las elecciones generales en los pueblos andinos, 1813-1814. In: ANNINO, Antonio (coord.), op. cit., p. 291-313; e ALJOVÍN DE LOSADA, Cristóbal. Sufragio y participación política Perú: 1808-1896. In: ALJOVÍN DE LOSADA, Cristóbal \& LÓPEZ, Silésio (ed.). Historia de las elecciones en el Perú: Estudios sobre el gobierno representativo. Lima: IEP, 2005, p. 19-75.

33 Constitución política de la monarquía..., op. cit., p. 28-29.
} 
y Villa Orellana) cuyos integrantes mantenían representación como alcaldes ordinarios de primer y segundo voto, así como procuradores síndicos (los cargos de mayor poder), mermó luego de 1812.

\section{Disputas territoriales y ciudadanía}

Otro aspecto que conviene destacar tiene que ver con el uso del censo de 1813 como recurso dentro de las disputas jurisdiccionales ocasionadas por las propias contingencias del sistema administrativo de corregimientos; o por las pretensiones de hegemonía territorial de los cabildos de las ciudades más grandes, sobre circunscripciones aledañas y de menor tamaño. La agregación de poblaciones realizada en el conteo poblacional redibujaba dichas aspiraciones:

Censo de la Provincia de Quito, sin incluir a Popayán, Cali, Buga, Caloto, Almaguer, y el Rapozo, en atención a sus actuales circunstancias, y pasando por la errada numeración que da esta capital a la cortizima población de 20.619 yndividuo[s]. 465.840.

Se deducen los 65.840 de personas que o no son ciudadanos o no están en exercicio de sus derechos, y quedan 400.000 .

Corresponden a este número 5 diputados en cortes, a razón de uno por cada 70.000, y sobran todavía 50.000 habitantes, a que por el art. 32 de la Constitución corresponde a un diputado más. ${ }^{34}$

En vista de estas circunstancias, cabe considerar el censo de 1813 como expresión de un esfuerzo normativo de control sobre una determinada entidad político-administrativa (la audiencia), pero también como cristalización de un ánimo de vinculación jurisdiccional de otros espacios regionales. Al incluir en sus conteos la población de otras periferias territoriales y sociales, se hacía patente que la soberanía territorial era tomada como un referente que permitía adelantar sobre un conjunto de expectativas regionales que estaban en disputa. Al incluir estos espacios dentro de la jurisdicción de la audiencia, se efectuaba sobre el papel una incorporación nominal. ${ }^{35}$

Además, la implantación del constitucionalismo doceañista en la audiencia de Quito, desencadenó un primer ejercicio moderno de homogeneización social normativa, ${ }^{36}$ al legalizar prácticas de ciudadanía prefijadas por

\footnotetext{
${ }^{34}$ ANH-Q, serie Gobierno, caja 63, 26-VIII-1813, ff. 19. La ortografía consta así en el original.

${ }^{35}$ MAIGUASHCA, Juan. El proceso de integración..., op. cit.

${ }^{36}$ MAIGUASHCA, Juan. El proceso de integración..., op. cit.
} 
nociones locales de pertenencia que ya eran legítimas, bajo la contingente definición de vecindad y que estaban acordes con intereses locales de traslape de unas poblaciones sobre otras, en virtud del ejercicio de su representación política previa.

Estas representaciones políticas eran funcionales, a su vez, a los juegos de poder en los que las élites locales y regionales estaban inmersos. Tal esfuerzo buscaba determinar, de la manera más acotada posible, el número de personas con posibilidad de ejercer la ciudadanía como derecho. Lo cual podía lograrse a través de un censo poblacional que permitiese reconstruir el universo de sujetos políticos y el de aquellos que no lo eran, aunque sus lineamientos dependieran siempre de las constataciones locales que revestían la vecindad. ${ }^{37}$

\section{Para concluir}

El censo ordenado por Torivio Montes en 1813 permite ilustrar el acoplamiento de la ciudadanía constitucional gaditana al bastidor fiscal del estado borbónico. Al componer registros censales a partir de padrones locales, conteos fiscales y de la división administrativa del sistema de corregimientos, los trazos tributarios borbónicos de la población y el dibujo normativo propuesto por la ciudadanía gaditana se solaparon. Los sujetos tributarios transitaron hacia ella en función del reforzamiento de los marcos administrativos previamente entablados por el sistema de las Cajas Reales de los antiguos corregimientos.

El ejercicio censal permitía limitar el monopolio jurisdiccional y administrativo de los municipios de las sedes de corregimientos como Quito, Riobamba, Cuenca o Guayaquil, al identificar poblaciones periféricas que tuviesen el coeficiente poblacional necesario para establecer ayuntamientos constitucionales. Y, por lo tanto, configurar sus propios espacios de representación local; además de estimular la urdimbre de nuevas relaciones de poder

\footnotetext{
37 El régimen administrativo de intendencias ensayado más luego por el emergente estado grancolombiano acudió también al censo como mecanismo de transcripción del valor político del territorio en función de la necesidad de crear parroquias y cantones, y para establecer el número de votantes dentro de cada departamento, no solo en vista de las elecciones de sus representantes al congreso, sino también en función de la integración de esos nuevos espacios de gobierno local. Registro de elecciones para la formación de cabildos. Guayaquil, 22 de septiembre de 1822. Archivo Histórico del Ministerio de Cultura y Patrimonio, fondo Ciencias Humanas, rollo 33/68, 1822-1823, f. 82.
} 
con base en la emergencia de estos nuevos espacios de gobierno, también usados como lugares de reproducción del poder local.

Cosa similar ocurrió con las agregaciones hechas al censo constitucional con padrones y padroncillos, levantados durante la época borbónica. Dichas agregaciones configuraron un panorama territorial de la participación político-constitucional basado, también, en los trazados jurisdiccionales y poblacionales de los corregimientos.

Finalmente, la homogeneización normativa promovida por el constitucionalismo doceañista en el espacio quiteño, no solo amplió la participación política por medio de la ciudadanía como mecanismo de integración social. También fue una herramienta útil para reconstituir el paisaje del poder local. ${ }^{38}$ La incorporación de los indígenas a los nuevos marcos de la ciudadanía, en lugar de fortalecer los dispositivos institucionales que proponía la Junta Superior de 1810, por ejemplo, desestructuró los fundamentos del poder regional quiteño y estimuló la emergencia de nuevas alianzas y actores políticos que, incluso, accedieron a la representación municipal, como ediles, gracias a las reformas doceañistas.

\section{Referencias bibliográficas \\ Fuentes primarias}

Archivo Histórico del Ministerio de Cultura y Patrimonio (AHMCP), Fondo de Ciencias Humanas Jacinto Jijón y Caamaño, Rollo 33/68.

Archivo Nacional Histórico, Quito (ANH-Q), Serie Gobierno, cajas 63 y 68.

\section{Otros materiales}

CEVALLOS, Pedro Fermín. Resumen de historia del Ecuador: Desde su origen hasta 1845, vol. 3. Quito: Imprenta de la Nación, 1886.

JUAN, Jorge \& ULLOA, Antonio. Noticias secretas de América, parte I. Sobre el estado militar y político de las costas del Mar Pacífico. Madrid-Quito: Turner / Libri Mundi, 1982.

\section{Bibliografía}

ALJOVÍN, Cristóbal. Ciudadano y vecino en Iberoamérica, 1750-1850: Monarquía o República. In: FERNÁNDEZ, Javier (dir.). Diccionario político y social del mundo iberoamericano: La era de las revoluciones, 1750-1850. Madrid: Fundación Carolina / Sociedad Estatal de Conmemoraciones Culturales / CEPC, 2009.

\footnotetext{
${ }^{38}$ MAIGUASHCA, Juan. El proceso de..., op. cit., p. 356. KÖNIG, Hans Joachim. Ciudadano Colombia-Nueva Granada. In: FERNÁNDEZ, Javier. Diccionario político..., op. cit., p. 234-245.
} 
ANDRIEN, Kenneth. The Kingdom of Quito, 1690-1830: The State and Regional Development. Cambridge: Cambridge University Press, 1995.

ANNINO, Antonio (coord.). Historia de las elecciones en Iberoaméricas Siglo XIX. Buenos Aires: Fondo de Cultura Económica, 1995.

BORRERO, Ana Luz. Cuenca en la Independencia de la fidelidad a la insurgencia: 1809-1824. Disertación de doctorado, UASB-E, 2016.

El legado de Cádiz: ciudadanía y cultura política en la Gobernación de Cuenca, 1812-1814. Procesos Revista ecuatoriana de historia, n. 39, ene-jun 2014, p. 9-36.

CABRERA Hanna, Santiago. Ciudadanía, representación política y territorio en la audiencia de Quito: entre el Pacto Solemne de 1812 y el censo poblacional de 1813. Memoria y Sociedad, vol. 20, n. 41, julio-diciembre 2016, p. 109-127. DOI: http://dx.doi.org/10.11144/Javeriana.mys20-41.crpt.

Repensando el Estado como institución. Poder central, cultura local y relaciones centro-periferia en las interpretaciones de Juan Maiguashca y el debate Schwarz-Carvalho Franco. Almanack, n. 13, 2016, p. 153-183. DOI: http://dx.doi.org/10.1590/2236-463320161308.

CORONEL, Rosario. Poder local entre la colonia y la república: Riobamba, 1750-1812. Quito: UASB-E / Corporación Editora Nacional, 2015.

DEMÉLAS, Marie-Danielle $\mathcal{E}$ SAINT-GEOURS, Yves. Jerusalén y Babilonia: Religión y política en el Ecuador, 1780-1880. Quito: IFEA / Corporación Editora Nacional, 1988.

DEMÉLAS, Marie-Danielle. Modalidades y significación de las elecciones generales en los pueblos andinos, 1813-1814. In: ANNINO, Antonio (coord.). Historia de las elecciones en Iberoamérica Siglo XIX. Buenos Aires: Fondo de Cultura Económica, 1995.

DYM, Jordana. Actas de independencia: de la Capitanía General de Guatemala a la República Federal de Guatemala. In: PALACIOS, Marco (ed.). Las independencias hispanoamericanas. Interpretaciones 200 años después. Bogotá: Grupo Editorial Norma, 2009.

From Sovereign Villages to National States: City, State and Federation in Central America, 1759-1839. Albuquerque: University of Mexico Press, 2006.

FERNÁNDEZ, Javier (dir.). Diccionario político y social del mundo iberoamericano: La era de las revoluciones, 1750-1850. Madrid: Fundación Carolina / Sociedad Estatal de Conmemoraciones Culturales / CEPC, 2009.

GUERRA, François-Xavier. Modernidad e independencias: Ensayos sobre las revoluciones hispánicas. Ciudad de México: Mapfre / Fondo de Cultura Económica, 2010.

HERZOG, Tamar.Vecinosyextranjeros:Hacerseespañolen laedadmoderna. Madrid:Alianza, 2006.

KÖNIG, Hans Joachim. Ciudadano Colombia-Nueva Granada. In: FERNÁNDEZ, Javier Fernández (dir.). Diccionario político y social del mundo iberoamericano: La era de las revoluciones, 1750-1850. Madrid: Fundación Carolina / Sociedad Estatal de Conmemoraciones Culturales / CEPC, 2009.

LYNCH, John. Dios en el Nuevo Mundo: Historia de la Iglesia de América Latina. Barcelona: Crítica, 2012.

MAIGUASHCA, Juan. El proceso de integración nacional en el Ecuador: el rol del poder central, 1830-1895. In: Idem. Historia y región en el Ecuador: 1830-1930. Quito: Flacso-Cerlac / York University / IFEA / Corporación Editora Nacional, 1994. 
MINCHOM, Martin. La evolución demográfica del Ecuador en el siglo XIX. Cultura, vol. VIII, n. 24 b, enero-abril 1986, p. 459-480.

MORELLI, Federica. Pueblos, alcaldes y municipios: la justicia local en el mundo hispánico entre Antiguo Régimen y Liberalismo. Revista Historia Crítica, n. 36, julio-diciembre 2008, p. 36-57.

. La Revolución en Quito: el camino hacia el gobierno mixto. Revista de Indias, vol. LXII, n. 225, 2002, p. 335-356.

Territorio o nación: Reforma y disolución del espacio imperial en Ecuador, 17651830. Madrid: CEPC, 2005.

ORTIZ DE LA TABLA DUCASSE, Javier. La población tributaria del Ecuador colonial. Cultura, vol. VIII, n. 24 b, enero-abril 1986, p. 447-458.

PALACIOS, Marco (ed.). Las independencias hispanoamericanas: Interpretaciones 200 años después. Bogotá: Grupo Editorial Norma, 2009.

PRADO JR., Caio. Formação do Brasil contemporâneo: Colônia. São Paulo: Companhia das Letras, 2011.

RODRÍGUEZ O., Jaime E. La revolución política durante la época de la independencia: El Reino de Quito 1808-1822. Quito: UASB-E / Corporación Editora Nacional, 2006. . La independencia de la América española. México: Fondo de Cultura Económica, 2005.

RODRÍGUEZ, Linda Alexander. Las finanzas públicas en el Ecuador (1830-1940). Quito: Banco Central del Ecuador, 1992.

SAINT-GEOURS, Yves. La evolución demográfica del Ecuador en el siglo XIX. Cultura, vol. VIII, n. 24 b, enero-abril 1986, p. 481-492.

La Iglesia en la Independencia. In: CARRERA DAMAS, Germán (ed.). Historia de América Andina: Crisis del régimen colonial e independencia, vol. 4. Quito: UASB-E / Libresa, 2003.

TERNAVASIO, Marcela. La revolución del voto: Política y elecciones en Buenos Aires, 18101852. Buenos Aires: Siglo Veintiuno, 2002.

VELASCO HERRERA, Viviana. Negociar el poder: Fiscalidad y administración pública en el proceso de construcción del Estado ecuatoriano, 1830-1875. Disertación de doctorado, Universitat Pompeu Fabra, 2013. 